\title{
The impact of enrollment in a specialized interdisciplinary neuropathic pain clinic
}

\author{
Alex Garven, Shauna Brady RN BN MN, Susan Wood RN, Melinda Hatfield MSW, \\ Jennifer Bestard MSc MD, Lawrence Korngut MD, Cory Toth MD
}

\begin{abstract}
A Garven, S Brady, S Wood, et al. The impact of enrollment in a specialized interdisciplinary neuropathic pain clinic. Pain Res Manage 2011;16(3):159-168.
\end{abstract}

BACKGROUND: Chronic pain clinics have been created because of the increasing recognition of chronic pain as a very common, debilitating condition that requires specialized care. Neuropathic pain $(\mathrm{NeP})$ is a multifaceted, specialized form of chronic pain that often requires input from multiple disciplines for assessment and management.

OBJECTIVE: To determine the impact of an interdisciplinary clinic for evaluation and treatment of patients with $\mathrm{NeP}$.

METHODS: Patients with heterogeneous etiologies for $\mathrm{NeP}$ were prospectively evaluated using an interdisciplinary approach every six months. Diagnostic evaluation, comorbidity evaluation, education, and pharmacological and/or nonpharmacological management were completed. Severity (visual analogue scale) and features of pain (Modified Brief Pain Inventory), sleep difficulties (Medical Outcomes Study - Sleep Scale), mood/anxiety disruption (Hospital Anxiety and Depression Scale), quality of life (European Quality-of-Life Five-Domain index), health care resources use, patient satisfaction (Pain Treatment Satisfaction Scale and Neuropathic Pain Symptom Inventory) and self-perceived change in well-being (Patient Global Impression of Change scale) were examined at each visit.

RESULTS: Pain severity only decreased after one year of follow-up, while anxiety and quality-of-life indexes improved after six months. Moderate improvements of sleep disturbance, less frequent medication use and reduced health care resource use were observed during enrollment at the $\mathrm{NeP}$ clinic.

DISCUSSION: Despite the limitations of performing a real-world, uncontrolled study, patients with $\mathrm{NeP}$ benefit from enrollment in a small interdisciplinary clinic. Education and a complete diagnostic evaluation are hypothesized to lead to improvements in anxiety and, subsequently, pain severity. Questions remain regarding the long-term maintenance of these improvements and the optimal structure of specialized pain clinics.

Key Words: Interdisciplinary clinic; Intervention; Medication; Neuropathic pain

$\mathrm{O}$ ver time, chronic pain has progressively been recognized, managed and cared for as a chronic disease process (1). As such, optimal outcomes in the management of persistent pain are not achieved by simply attempting to remove the source of the pain but, rather, through addressing both consequences of and contributors to the disease of persistent pain. Once initiated, chronic pain awakens the development of complex associated conditions affecting physical and psychosocial function, including sleep disturbance, poor appetite, medication dependence, mood disorders, anxiety disorders, inappropriate health care resource use (HCRU), poor work performance, isolation, immobility, fatigue, frustration, depression and suicide (2). A patient's perceptions and responses to illness also play a role in the

\section{Les effets de la participation à une clinique interdisciplinaire spécialisée de la douleur névropathique}

HISTORIQUE : Les cliniques de douleur chronique ont été créées parce qu'on constate de plus en plus à quel point la douleur chronique est un trouble très courant et débilitant qui exige des soins spécialisés. La douleur névropathique ( $\mathrm{DNe}$ ) est une forme spécialisée et pluridimensionnelle de douleur chronique qui exige souvent l'apport de multiples disciplines en vue de son évaluation et de sa prise en charge.

OBJECTIF : Déterminer l'effet d'une clinique interdisciplinaire pour le traitement des patients ayant des DNe.

MÉTHODOLOGIE : Tous les six mois, les chercheurs ont fait une évaluation prospective des patients ayant des étiologies hétérogènes de $\mathrm{DNe}$ au moyen d'une démarche interdisciplinaire. Ils ont procédé à l'évaluation du diagnostic, l'évaluation des comorbidités, l'éducation et la prise en charge pharmacologique et non pharmacologique. À chaque visite, ils ont examiné la gravité (échelle analogique visuelle) et les caractéristiques de la douleur (bref inventaire modifié de la douleur), les troubles du sommeil (étude des issues médicales - échelle de sommeil), les perturbations de l'humeur et de l'anxiété (échelle d'anxiété et de dépression à l'hôpital), la qualité de vie (indice européen des cinq domaines de qualité de vie), l'utilisation de ressources de santé, la satisfaction du patient (échelle de satisfaction du traitement de la douleur et inventaire des symptômes de douleur névropathique) et le changement autoperçu de bien-être (échelle d'impression globale de changement de la part du patient).

RÉSULTATS : La gravité de la douleur ne diminuait qu'après un an de suivi, tandis que les indices d'anxiété et de qualité de vie s'amélioraient au bout de six mois. On observait une diminution modérée des troubles du sommeil, une consommation moins fréquente de médicaments et une moins grande utilisation des ressources de santé pendant l'inscription à la clinique de DNe. EXPOSÉ : Malgré les limites liées à une étude non contrôlée en milieu réel, les patients ayant des $\mathrm{DNe}$ profitaient de leur participation à une petite clinique interdisciplinaire. On postule que l'éducation et une évaluation diagnostique complète suscitent des diminutions de l'anxiété et, ultérieurement, de la gravité de la douleur. Des questions se posent encore quant au maintien à long terme de ces améliorations et à la structure optimale des cliniques spécialisées de la douleur.

clinical presentation (3). Therefore, chronic pain forces a profound burden on patients, their families and employers, and the health care system (4), particularly when the prevalence of Canadians suffering from a form of chronic pain is up to one in three (5). The burden of chronic pain can be eased when applicable knowledge is applied and provided. If it is not, the aging Canadian population will contribute to increased disability due to chronic pain and the ongoing health care financial crisis (2).

One form of chronic pain is neuropathic pain $(\mathrm{NeP})$, which refers to pain initiated or caused by a primary lesion or dysfunction of the nervous system (6). NeP can be due to a wide variety of etiologies, and its features include dysesthesias, allodynia and hyperalgesia (7). 
Symptoms of $\mathrm{NeP}$ can be continuous or paroxysmal (8). NeP can be difficult to manage, even with multiple available pharmacological therapies. Chronic NeP has a negative impact on quality of life in several domains because concomitant mood and sleep disorders often coexist (9-12). The presence of multiple health concerns for individual patients has contributed to great management difficulties, often requiring the input of multiple caregivers with different health care provider backgrounds.

One solution that has developed over time is the creation of interdisciplinary clinics, which can more effectively address the requirements of individual patients, rather than simply focusing on the underlying disease or single condition (13). The multiple etiologies of $\mathrm{NeP}$ also mandate a comprehensive multimodal approach focused on education, coping skills and relapse training (14); an interdisciplinary team approach is often considered to be optimal $(14,15)$. The first such program was instituted half a century ago by John J Bonica, who integrated the efforts of several health care providers to assist patient function, alleviate pain and improve pain management skills (16). Multidisciplinary treatment is defined as treatment by health care providers in more than one health care discipline, without a specific need for one discipline to synchronize therapy amongst all of them (17). This differs somewhat from interdisciplinary treatment, which involves coordinated interventions among health care providers in a variety of disciplines, who work together in the same physical location in an integrated fashion, with joint goals and ongoing communication (18). As such, interdisciplinary pain treatment considers the patient to be an active participant who is assuming significant responsibility within the treatment process $(16,19)$. An interdisciplinary program may have advantages related to greater integration of joint treatment goals $(18,20)$.

In late 2006, based on the International Association for the Study of Pain guidelines (13), we devised an interdisciplinary clinic for the assessment and management of patients with NeP. It is called the Neuropathic Pain Clinic (NePC) and is located at the Foothills Medical Centre (Calgary, Alberta). This clinic was the first of its kind in Canada. Although it was anticipated that the development of multidisciplinary/interdisciplinary clinics would be supported by evidence, studies conducted to determine the impact and effectiveness of multidisciplinary/interdisciplinary chronic pain clinics have reported conflicting results (21-25). In fact, questions have been raised regarding the efficacy and cost effectiveness of these clinics $(26,27)$. Although qualitative reviews $(25,28-30)$ have generally supported the value of multidisciplinary pain clinics, methodological concerns are expressed. In response, we have conducted objective measures of pain, quality of life, HCRU and ancillary conditions before enrollment in our interdisciplinary clinic and at subsequent sequential assessment time points.

The aim of the present study was to determine the impact of an $\mathrm{NePC}$ on pain and related features in a population of patients with $\mathrm{NeP}$ due to various causes. We hypothesized that the NePC would have a positive impact on levels of pain, quality of life and HCRU in our population of patients with $\mathrm{NeP}$. Our secondary objective was to determine the potential for a positive impact on ancillary measures of sleep, pain qualification and interference features, patient satisfaction, patients' impressions of changes to their condition, and mood and anxiety disorders frequently associated with NeP. Assessment of the impact of a multidisciplinary clinic such as the NePC is challenging - the identification of an appropriate patient control group is often not possible; we also did not identify an appropriate control group for the present study. Patients attending these clinics often seek medical attention outside of the multidisciplinary clinic, leading to confounding effects. In addition, patients with chronic pain have sought medical attention with multiple interventions several times before their presentation to a multidisciplinary clinic in most cases, which may have an impact on their own feelings of futility or hope. Finally, patients initiated their care at the multidisciplinary clinic while already on therapies initiated elsewhere. All of these factors may contribute to an impact on effect sizes, the validity of data obtained, and the ability to generalize specific or nonspecific findings. A review of the present study's data requires consideration of all these implicit factors.

\section{The interdisciplinary clinic}

\section{METHODS}

The components of the interdisciplinary clinic used for the present study were located at the Foothills Medical Centre in Calgary, which has a referral base of 2.5 million people in southern Alberta. The medical director was responsible for the overall performance of the clinic, triaging of patient referrals received at the clinic and the direction of the clinic based on monthly health professional visits. Each of the physicians (including the medical director) conducted a comprehensive assessment of patients, providing focused and careful neurological and musculoskeletal examinations, a review of previous medical and surgical interventions, and the diagnosis and management of $\mathrm{NeP}$ conditions. The $\mathrm{NePC}$ was not associated with delivery of invasive therapies such as nerve blocks or implanting devices. Nurses of patients attending the $\mathrm{NePC}$ were responsible for gathering patient histories, evaluating lifestyle issues impacting patients and their response to treatment, and monitoring medication use and comorbidities. They also played a critical role in the coordination of care as case managers, providing education and streamlining access to medical therapy. Kinesiologists provided comprehensive assessments of strength, flexibility, physical endurance, range of motion, and gait and postural abnormalities. The clinic's social worker provided education regarding active physical coping skills and facilitated treatment planning through comprehensive assessments of the patient's psychosocial functioning, personality, psychopathology, social support, level of motivation and coping resources. Each patient had a minimum of two health professionals (physician and nurse) involved in his or her care; up to four health professionals (additional kinesiologist and social workers) participated in caring for the individual patient. Consultations with kinesiologists depended on a patient's mobility and willingness to participate. Access to a social worker depended on additional needs for social support, psychological input and assistance for coping, as well as the patient's willingness to participate.

\section{Patient assessment}

Patients with $\mathrm{NeP}$ in a tertiary care neuromuscular clinic in Calgary, Alberta, were prospectively evaluated. The present investigation was not designed to be a randomized study or a prospective cohort examination; rather, it was part of patients' regular clinical care. All patients enrolled within the NePC provided informed written consent for assessment of their clinical outcomes at regular follow-up visits, as approved by the local health research ethics board, with completion of questionnaires conducted at each follow-up visit (Centre for Advancement of Health, University of Calgary [Alberta]). All patients completed questionnaires before their clinical assessment on the day of participation. The DN4 questionnaire, which has good sensitivity (83\%) and specificity (90\%) (31), was used to confirm the presence of $\mathrm{NeP}$ - only patients with a score of 4 or greater were eligible to enrol in the $\mathrm{NePC}$ and participate in the present study. Patients with predominant forms of pain that were believed to arise from a non-neuropathic source were seen for a single NePC visit, but were redirected to another multidisciplinary chronic pain clinic for management of their symptoms. Patients with predominant $\mathrm{NeP}$ with other secondary causes of chronic pain were permitted to receive follow-up at the $\mathrm{NePC}$. Patients enrolled in the $\mathrm{NePC}$ were seen every six months after initial enrollment.

The NePC was designed to provide noninvasive assessment and management of NeP. The nature of the clinic's treatment goal was rehabilitative rather than curative for all patients, with emphasis placed on defined, realistic outcomes rather than impractical total pain relief. Instead of focusing principally on pain, the aim was to 
improve quality of life by increasing patient knowledge, coping and independence through goals to improve or restore physical, psychological, social and occupational functioning. The study also sought to decrease overdependence on drugs and other treatment modalities (32), and to decrease inappropriate use of the health care system (33). Pharmacological interventions, physical therapy, exercise therapy, family and social counselling, patient education or vocational counselling were offered; however, surgical or other invasive nonpharmacological modalities were not offered. Every attempt was made to simplify medication schedules, and to reduce or discontinue the use of medications being used in excessive dosages (above suggested dosing schedules) or medications leading to intolerant adverse effects impacting overall well-being, including the excessive use of opioids (34).

Pain and ancillary features were assessed using a selection of instruments (Table 1). During each clinic visit, clinical, psychological and overall well-being were assessed. Education regarding the specific clinical condition was provided verbally and in hard-copy form. Counselling was provided by specialized nursing staff or social workers, as required, for each individual case. Patients' current $\mathrm{NeP}$ medications and comorbidities at each visit were carefully recorded. Adverse events related to medications were reviewed at each visit. Patients enrolled in the clinic were appraised by the interdisciplinary team and decisions were made at the end of each visit regarding changes to nonpharmacological (including kinesiology assessments or management) or pharmacological management for $\mathrm{NeP}$ and related conditions. Decisions regarding management were made by the physician and patient, in concert, at the end of the visit. At the conclusion of each visit, information was provided to each patient regarding any new intervention to be considered, and patients were advised to contact the clinic if unexpected adverse effects occurred, or if they experienced clinical difficulties with pain or therapies during enrollment in the NePC. Each subsequent clinical follow-up occurred at six-month intervals unless urgent assessment was required at a shorter interval at the discretion of the patient and clinic team members. Patients were prospectively evaluated, beginning with the first clinic visit and sequentially following the results for each patient during all subsequent visits.

\section{Primary outcome measures}

At each visit, data pertaining to the primary outcome measures were tabulated for level of pain (visual analogue scale [VAS] pain score), quality of life (European Quality-of-Life Five-Domain [EQ-5D] index) and HCRU for each patient with $\mathrm{NeP}$. The degree of $\mathrm{NeP}$ severity was evaluated using a VAS with an unmarked $100 \mathrm{~mm}$ line between anchors of no pain on the left $($ score $=0)$ and worst possible pain on the right $($ score $=10)$, bisected by the patient. The marked score reflected the patient's average $\mathrm{NeP}$ severity experienced over the previous $24 \mathrm{~h}$. The VAS was scored by line measurement in each case.

The EQ-5D has two sections. The first section examines the health state in five domains: mobility, self-care, usual activities, pain/ complaints and anxiety/depression. The health status profile determined from these five domains is converted into a single utility score using a scoring algorithm based on interviews of general public members from a United Kingdom population (35), with utility scores ranging from -0.594 (indicating serious problems in all dimensions) to 1 (indicating no problems at all). The second section of the EQ-5D is the EQ-5D VAS, which measures the patient's perception of his or her overall health on a $100 \mathrm{~mm}$ VAS; a score of 0 indicates worst health and 100 represents their best imaginable health.

Each patient also completed an HCRU assessment for their use of medications, employment, health care visits (ie, surgery, primary physician or emergency room visits), diagnostic and treatment procedures, exercise, and pain and physical function.

\section{Secondary outcome measures}

Secondary outcomes consisted of additional pain assessments, mood, anxiety and sleep assessments, and questionnaires to assess patient
TABLE 1

Instruments for the assessment of general health in patients with neuropathic pain (NeP)

\begin{tabular}{lc}
\hline Instrument & Dimensions \\
\hline $\begin{array}{c}\text { European Quality-of-Life } \\
\text { Five-Domain index }\end{array}$ & $\begin{array}{c}\text { Five domains impacting quality of life (mobility, } \\
\text { self-care, usual activities, pain/complaints and } \\
\text { anxiety/depression) as well as a calculated } \\
\text { EQ-5D index score and EQ-5D visual analogue } \\
\text { scale health score }\end{array}$ \\
$\begin{array}{cc}\text { Visual analogue scale } & \text { Pain intensity: Likert scale from 0 (no pain) to } \\
\text { Health care resources } & \text { Multi-item questionnaire regarding use of health } \\
\text { use assessment } & \text { care resources, need for procedures, surgeries, } \\
& \text { compliance with therapies, ability to receive } \\
\text { therapies and ability to perform daily activities } \\
\text { Hospital Anxiety and } & \text { Survey on anxiety and depression } \\
\text { Depression Scale } & \\
\text { Patient Global Impression } & \text { 7-point scale for the patient to rate their own } \\
\text { of Change scale } & \text { well-being relative to the initial assessment } \\
\text { Pain Treatment } & \text { 14 dimensions of patient outlook on life, } \\
\text { Satisfaction Scale } & \text { satisfaction with medication usage and } \\
\text { Study - Sleep Scale } & \text { satisfaction with disease control/relief } \\
\text { Mouropathic Pain } & \text { 12-item self-report characterization and } \\
\text { Inventory } & \text { Pain intensity, interference with function, pain } \\
\text { Medical Outcomes } & \text { relief, pain qualities and patient's perception of } \\
\text { the cause of pain }\end{array}$ \\
\hline
\end{tabular}

satisfaction and impression of change in well-being. The Modified Brief Pain Inventory (MBPI [36]) provides information regarding pain intensity and the degree of pain interference with function, and inquires about pain relief, pain quality and the patient's perception of the cause of pain. The Medical Outcomes Study - Sleep Scale (MOS-SS [37]) is a 12-item self-report sleep measure that can be used to assess important aspects of sleep perceived by adults; domains within the MOS-SS permit analysis between time points. The Hospital Anxiety and Depression Scale (HADS [38]) is another self-assessment scale that has been found to be a reliable instrument for detecting states of depression (HADS-D) and anxiety (HADS-A) in the setting of an outpatient clinic. Its subscales are also valid measures of emotional disorder severity. The Neuropathic Pain Symptom Inventory (NPSI [39]) consists of 12 items regarding qualities and quantities of pain descriptions, as well as subscores (burning, pressing [deep], paroxysmal, evoked and paresthesias/dysesthesias) and a total score. The responsiveness of patients to an intervention was also categorized based on initial VAS scores. The Pain Treatment Satisfaction Scale (PTSS) assesses patient satisfaction with treatments provided (40). The Patient Global Impression of Change (PGIC) scale is a simple seven-point scale used to assess subjective change in patient wellbeing during the course of an intervention (41) - this test was administered beginning at the six-month follow-up visit.

\section{Tolerability and adverse events}

An adverse event was defined as any noxious, unintended or unexpected response suspected of having a causal relationship with the nonpharmacological or pharmacological intervention used. Serious adverse events were defined as any life-threatening reaction to intervention that required hospitalization or additional urgent physician assessment, or resulted in persistent or significant disability - these were recorded in a prospective manner.

\section{Data analysis}

Data were analyzed using matched ANOVA testing for each individual patient between follow-up time points for VAS pain scores, EQ-5D data, 


\begin{tabular}{|c|c|}
\hline \multicolumn{2}{|c|}{ NeP patients followed on three occasions ( $n=199)$} \\
\hline Female sex, n (\%) & $124(67)$ \\
\hline Age, years, mean \pm SD (range) & $52.4 \pm 8.2(26-89)$ \\
\hline Duration of NeP, years, mean $\pm \mathrm{SD}$ (range) & $3.8 \pm 6.1(0.6-12.8)$ \\
\hline \multicolumn{2}{|l|}{ Diagnosis, $\mathrm{n}$} \\
\hline Postsurgical/post-traumatic & 30 \\
\hline Diabetic polyneuropathy & 24 \\
\hline Other cause of polyneuropathy & 68 \\
\hline Trigeminal neuralgia/other facial pain & 13 \\
\hline Cervical/lumbar radiculopathy & 14 \\
\hline Multiple sclerosis & 7 \\
\hline Myelopathy & 5 \\
\hline Postherpetic neuralgia & 6 \\
\hline Brachial/lumbar plexopathy & 8 \\
\hline Complex regional pain syndrome & 4 \\
\hline Other & 3 \\
\hline No specific diagnosis or multiple causes & 17 \\
\hline \multicolumn{2}{|c|}{ NeP patients followed on only two occasions $(n=59)$} \\
\hline Female sex, n (\%) & $30(51)$ \\
\hline Age, years, mean $\pm \mathrm{SD}$ (range) & $49.7 \pm 10.3(24-62)$ \\
\hline Duration of NeP, years, mean $\pm \mathrm{SD}$ (range) & $3.6 \pm 8.2(0.9-11.7)$ \\
\hline \multicolumn{2}{|l|}{ Diagnosis, $\mathrm{n}$} \\
\hline Postsurgical/post-traumatic & 12 \\
\hline Diabetic polyneuropathy & 6 \\
\hline Other cause of polyneuropathy & 14 \\
\hline Trigeminal neuralgia/other facial pain & 2 \\
\hline Cervical/lumbar radiculopathy & 3 \\
\hline Multiple sclerosis & 1 \\
\hline Myelopathy & 2 \\
\hline Postherpetic neuralgia & 1 \\
\hline Brachial/lumbar plexopathy & 2 \\
\hline Complex regional pain syndrome & 3 \\
\hline Other & 13 \\
\hline
\end{tabular}

HCRU data, HADS total scores and subscores, PTSS data, MBPI data, MOS-SS subscores and total scores, and NPSI data. Bonferroni corrections were applied for situations when several independent tests were being conducted simultaneously. Missing data due to loss to follow-up or dismissal from the $\mathrm{NePC}$ were treated using the last observation carried forward in all cases, in an intention-to-treat format (as long as patients attended the clinic at least twice). The baseline pain VAS score was used for comparison with later pain scores. ORs were used to determine the likelihood of responsiveness for improvement of the primary outcome measures based on the baseline VAS pain score, grouped according to mild ( 0 to 30 ), moderate ( 31 to 69 ) and severe ( 70 to 100 ) pain. To examine individual patient VAS pain severity as a factor in pain responsiveness, probability for improvement in quality of life, and the PGIC, a logistic regression model was fit to model the odds for each level of pain severity at baseline. The estimated regression coefficients provided the log of estimated OR, with values of the estimated regression coefficient close to zero relating to an OR of close to one, suggesting no effect of pain severity on outcome measure. The $95 \% \mathrm{CI}$ was also calculated for each OR. PGIC scales were analyzed between follow-up points using a modified ridit (Relative to an Identified Distribution) transformation with the Cochran-Mantel-Haenszel procedure, with adjustment for centre. Data concerning serious adverse effects and presence of comorbidities were tabulated. Data for the number of medications used at each time point for $\mathrm{NeP}$ were analyzed using matched ANOVA testing.

\section{RESULTS}

A total of 199 patients with $\mathrm{NeP}$ attended the clinic on three separate occasions at six-month intervals (mean [ \pm SD] age $52 \pm 8$ years [range 26 to 89 years]; 124 females), while another 59 patients with $\mathrm{NeP}$ only attended on two occasions (Table 2 and Figure 1). Forty-six patients with non-NeP (ie, nociceptive pain) and six patients with $\mathrm{NeP}$ attended the clinic on one occasion only. Data for patients with $\mathrm{NeP}$ who only attended the $\mathrm{NePC}$ on two occasions were maintained and carried forward for all measurements described.

The total number of physicians seen during the previous six-month period of time decreased after admission to the NePC for visit 3 (Figure 1). Also, the number of medications used for $\mathrm{NeP}$ decreased for patients who continued their visits to the NePC. Patient satisfaction with the use of pain medications indicated significant improvements of self-reported subjective satisfaction with the amount and frequency of medication use after visits 2 and 3, respectively (Table 3 and Figure 1). Additionally, the level and duration of pain relief were improved at visit 3; however, other components of the PTSS failed to improve on future visits to the $\mathrm{NePC}$. Also, there were no significant improvements noted for any of the individual pain qualifiers within the NPSI.

Self-reported pain intensity and interference of pain with function identified some improvements of the level and severity of pain over the previous $24 \mathrm{~h}$, and reduced interference of pain with general activities, mood and sleep (Table 4). However, there were no significant improvements in remaining categories of interference with regular activities.

The severity of pain recorded using the VAS pain values only achieved significant improvement on the third visit to the NePC (Figure 2). The EQ-5D domains of pain/discomfort and anxiety/ depression improved on the third visit to the $\mathrm{NePC}$ compared with the initial EQ-5D scores (Figure 3). Also, there were significant improvements of the EQ-5D index and EQ-5D VAS health scale scores on each of the second and third visits to the NePC (Figure 3).

The HADS-A survey demonstrated improvement of anxiety on visit 2, with further improvement of the HADS-A score on visit 3 (Figure 4). However, there was no specific improvement of the HADS-D score throughout the visits. HADS total scores were improved at visit 3, mainly due to lower HADS-A scores. Despite improvements of mood and anxiety, there was only one category of improved sleep using the MOS-SS subscales - the level of sleep disturbance. The overall sleep problems index was unchanged (Table 5).

Patients were asked to provide their PGIC during visits 2 and 3. At visit 3 , there was significant improvement of overall subjective global change reported by NePC patients (Figure 5) compared with their reported results from visit 2 .

The HCRU assessment identified some reduction of the performance of outpatient surgeries/procedures, emergency room admissions and the number of other outpatient doctor visits at visit 3 for the NePC patient population (Table 6). However, other aspects of $\mathrm{NeP}$ that could have an impact on HCRU were not significantly different at visit 3 for the NePC patient population, including the number of hospitalizations, the number of outpatient diagnostic procedures, the number of missed appointments, the impact on the amount of work performed and the impact on daily activities, among other measures.

Pain severity was analyzed at baseline as a factor in primary outcome variables. Higher levels of initial pain severity were associated with improved VAS pain severity at visit 3 (one year of follow-up) and a greater likelihood of improvement in the EQ-5D index score, but were not associated with enhanced PGIC outcomes as demonstrated in a forest plot (Figure 6) obtained and compared between visits 2 and 3.

Comorbidities for all patients are included in the Appendix. Serious adverse events occurred in a total of three patients, all of whom were seen at the emergency room for purported side effects of prescribed medications. One patient developed pretibial edema during pregabalin treatment requiring discontinuation with subsequent resolution. A second patient presented to the emergency room with obtundation, which subsequently resolved over the next three days 


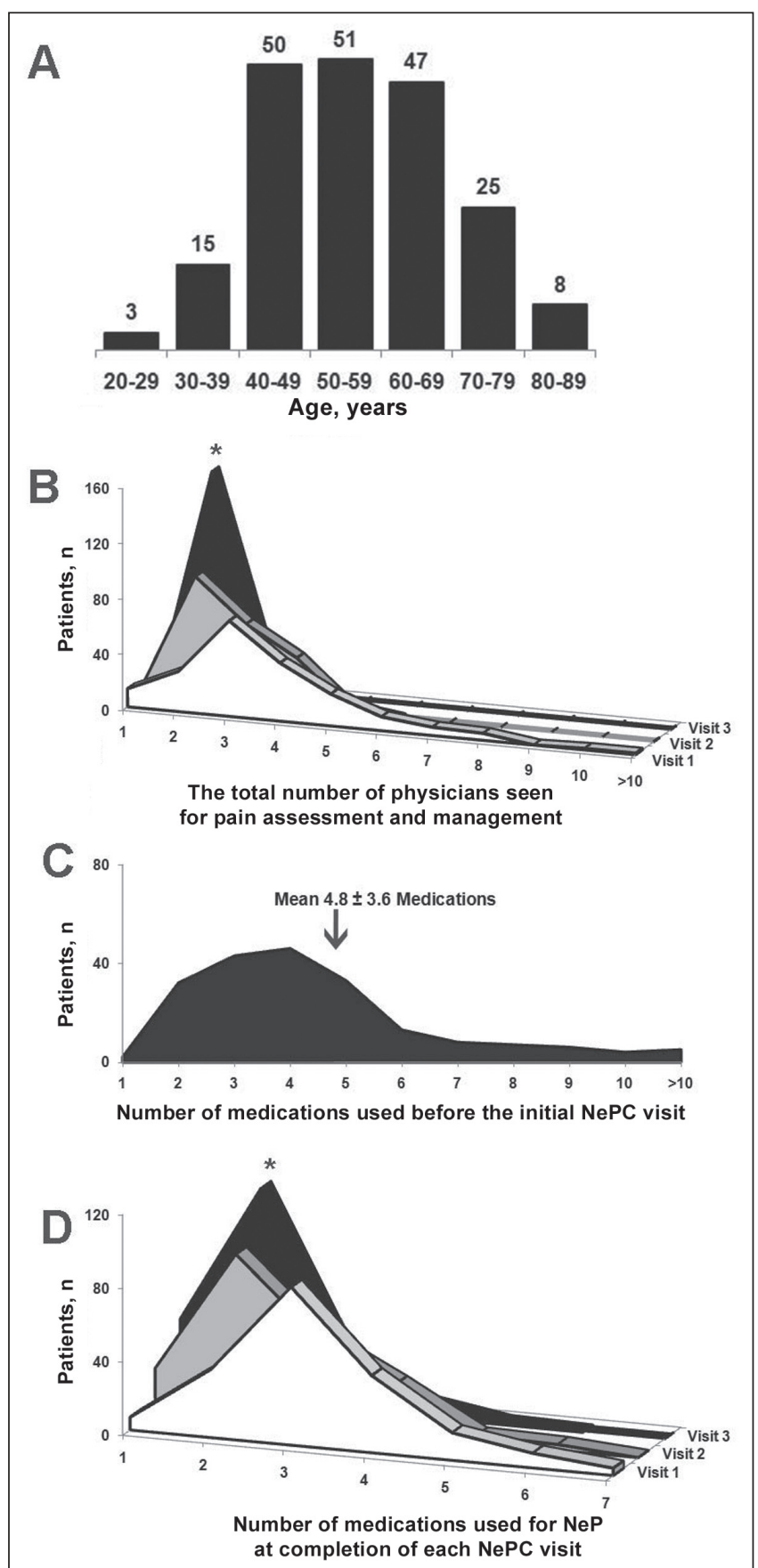

Figure 1) A Age distribution for neuropathic pain (NeP) patients completing one year of follow-up at the Neuropathic Pain Clinic (NePC; Calgary, Alberta). The distribution was bell shaped and most patients were 40 to 70 years of age. B The total number of physicians seen for pain management (including their primary physician at the NePC) of patients maintaining follow-up at the NePC decreased over the course of one year (matched ANOVA: $* P<0.05)$. C The number of medications used for pain before the initial NePC visit was high, averaging nearly five medications for each patient. D At the completion of each NePC visit, the number of medications used decreased over time, with a significant medication number decrease by the end of visit 3 (matched ANOVA: $* P<0.05$ )

with discontinuation of $0.5 \mathrm{mg}$ per oral nabilone. A third patient tripped while climbing stairs on her way to exercise therapy in the kinesiology department, and required emergency room assessment and conservative therapy for soft tissue injuries.
TABLE 3

Improvements made regarding patient self-reported satisfaction in terms of medication use and related pain relief within the Pain Treatment Satisfaction Scale (PTSS)

score

\begin{tabular}{|c|c|c|c|}
\hline PTSS question & Visit 1 & Visit 2 & Visit 3 \\
\hline 11. Satisfied with amount of medication & $3.12 \pm 0.09$ & $2.80 \pm 0.11^{*}$ & $2.73 \pm 0.13^{\dagger}$ \\
\hline $\begin{array}{l}\text { 13. Satisfied with level of pain relief } \\
\text { with medication }\end{array}$ & $3.18 \pm 0.09$ & $3.01 \pm 0.12$ & $2.78 \pm 0.14^{\dagger}$ \\
\hline $\begin{array}{l}\text { 14. Satisfied with duration of pain relief } \\
\text { with medication }\end{array}$ & $3.24 \pm 0.09$ & $3.03 \pm 0.12$ & $2.68 \pm 0.15^{\dagger}$ \\
\hline
\end{tabular}

Data presented as mean $\pm S D$. Bonferroni corrections were applied for the 14 different questions posed. Data with statistical significance are displayed in bold. To maintain brevity, questions not achieving statistical significance are not presented. ${ }^{*}$ Matched ANOVA: $P<0.05$ between visits 1 and $2 ;{ }^{\dagger}$ Matched ANOVA: $P<0.0035$ between visits 1 and 3

\section{TABLE 4}

Self-reported improvements made regarding the impact of pain interfering with normal activities based on the Modified Brief Pain Inventory (MBPI) at visit 3

\begin{tabular}{|c|c|c|c|}
\hline MBPI question & Visit 1 & Visit 2 & Visit 3 \\
\hline 2. Pain right now & $5.01 \pm 0.19$ & $5.16 \pm 0.26$ & $4.18 \pm 0.25^{\star}$ \\
\hline 3. Worst pain in past $24 \mathrm{~h}$ & $7.12 \pm 0.18$ & $7.04 \pm 0.26$ & $6.31 \pm 0.28^{\star}$ \\
\hline 5. Average pain in past $24 \mathrm{~h}$ & $5.44 \pm 0.17$ & $5.27 \pm 0.23$ & $4.72 \pm 0.24^{\star}$ \\
\hline 6a. Pain interference with general activity & $5.70 \pm 0.24$ & $5.81 \pm 0.31$ & $4.54 \pm 0.36^{\star}$ \\
\hline 6b. Pain interference with mood & $5.29 \pm 0.25$ & $4.87 \pm 0.32$ & $4.26 \pm 0.31^{\star}$ \\
\hline 6e. Pain interference with sleep & $5.89 \pm 0.25$ & $5.70 \pm 0.32$ & $4.85 \pm 0.31^{\star}$ \\
\hline
\end{tabular}

Data presented as mean $\pm S D$. Bonferroni corrections were applied for the 12 different questions posed. Data with statistical significance are displayed in bold. To maintain brevity, questions not achieving statistical significance are not presented. ${ }^{*}$ Matched ANOVA: $P<0.0042$ between visits 1 and 3)

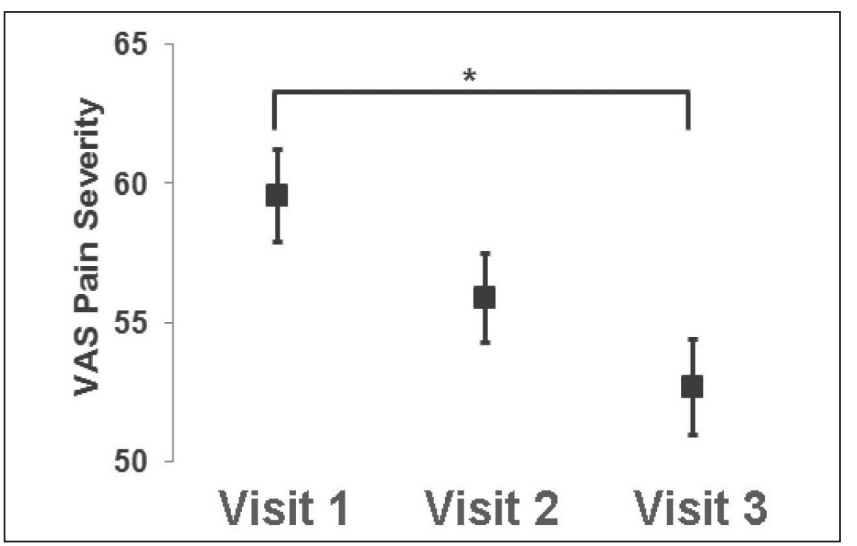

Figure 2) Visual analogue scale (VAS) pain severity. The severity of pain decreased over time, but did not significantly improve until visit 3 (matched ANOVA: $* P<0.05)$. Data presented as means with SE bars

\section{DISCUSSION}

It is proposed and assumed that the interdisciplinary cooperation of multiple forms of health care providers is helpful in the treatment of patients suffering from complex health problems (42). A meta-analysis assessing the interdisciplinary approach in a clinic (25) determined that interdisciplinary treatments are superior to no treatment, being on a waiting list and single-discipline treatment (ie, medical treatment or physical therapy) for reducing pain, improving activity level and mood, minimizing HCRU and medication intake, and facilitating a return to work. The greatest 


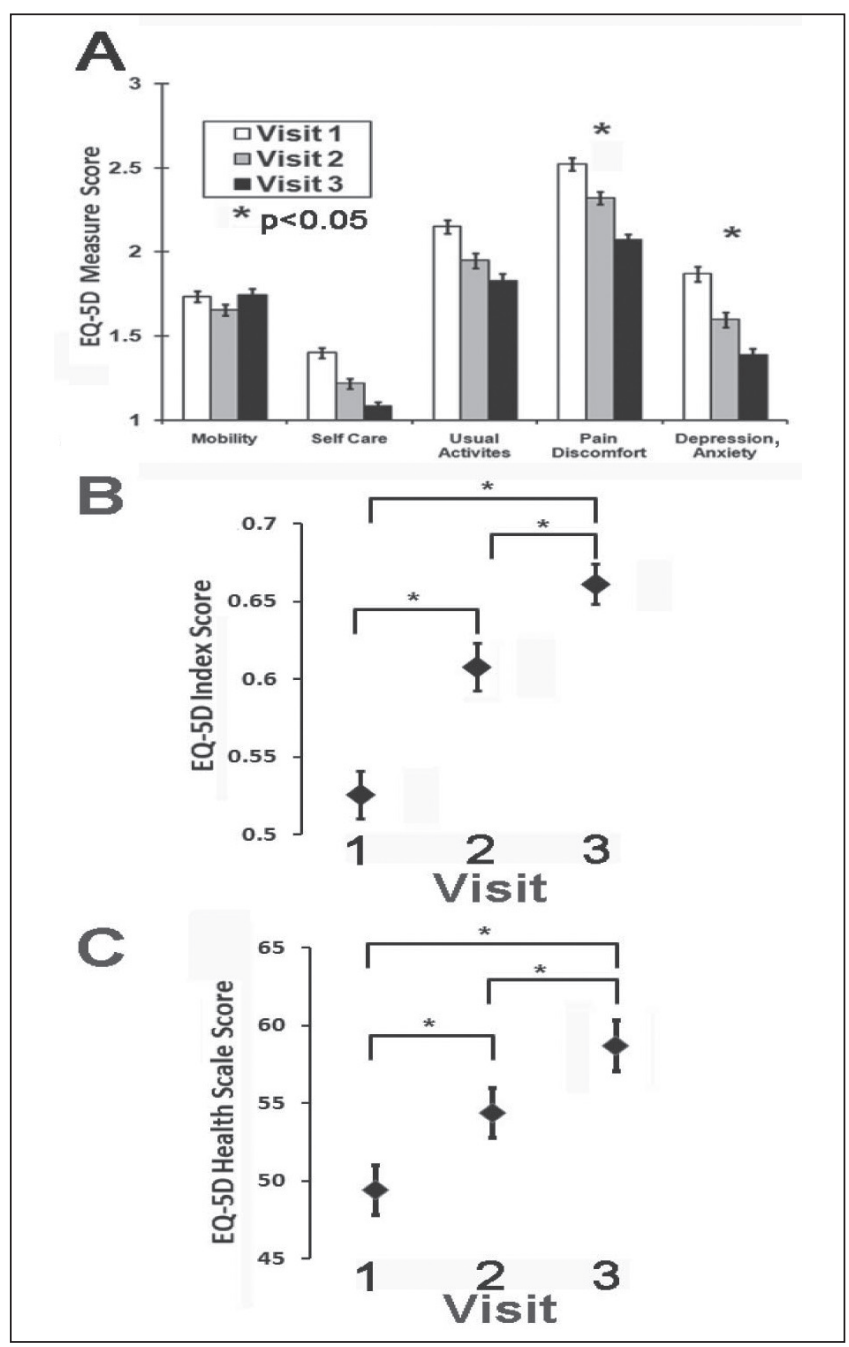

Figure 3) A A bar graph of the European Quality-of-Life Five-Domain (EQ-5D) index. The plot identified improvement in the pain/discomfort and depression/anxiety portions at visit 3 for enrolled patients (matched ANOVA: ${ }^{*} P<0.01$ after Bonferroni corrections were applied). B The EQ-5D index score demonstrated significant improvements at each of visits 2 and 3 for neuropathic pain patients (matched ANOVA: $* P<0.05$ ). $\mathrm{C}$ The EQ-5D visual analogue scale health score also demonstrated significant improvements at each of visits 2 and 3 for neuropathic pain patients (matched ANOVA: $* P<0.05$ ). Data presented as means with SE bars

obstacle to assessment of the role of interdisciplinary clinics is marginal methodological quality in most such studies (25). The sparse number of randomized, controlled trials has contributed to complexity in the assessment of interdisciplinary clinics for chronic pain. Furthermore, systematic reviews of randomized, controlled trial data have examined subsets of chronic pain that are not necessarily of neuropathic origin $(28-30,43)$. Although comparing the impact of different clinics would be desirable, the generalizability of the demonstrated impact of one pain program to another is limited due to differences in treatment, patient groups, forms of evaluation and different lengths of follow-up periods (44). There is also the question of when discharge from a pain clinic should occur because research has demonstrated that a loss of treatment effect may occur after 12 months (45). All of these controversies increase uncertainty regarding the optimal form of an interdisciplinary clinic and how the management of patients should be handled after they are discharged from pain clinics. Our study had similar limitations, with the greatest confounding factor being the absence of an appropriate control group for comparison.

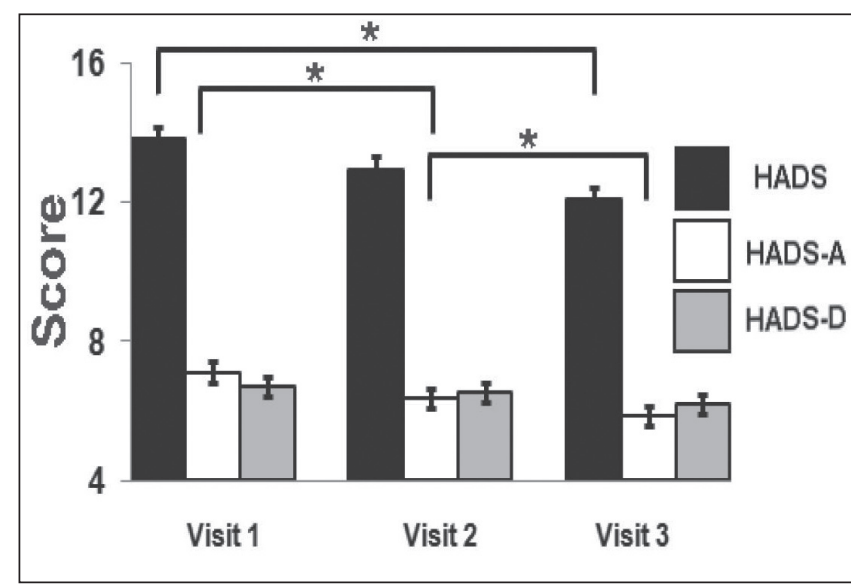

Figure 4) The Hospital Anxiety and Depression Scale (HADS) scores demonstrated an overall improvement after visit 3, while the HADS anxiety (HADS-A) subscore improved on each of visits 2 and 3 (matched ANOVAs: $* P<0.025$ after Bonferroni corrections were applied). The HADS depression (HADS-D) subscore did not demonstrate a significant improvement after visit 2 or visit 3. Data presented as means with SE bars

\section{TABLE 5}

\section{Medical Outcomes Study - Sleep Scale (MOS-SS)} subscores

\begin{tabular}{lccc}
\hline MOS-SS question & Visit 1 & Visit 2 & Visit 3 \\
\hline Sleep disturbance & $35.9 \pm 3.7$ & $33.7 \pm 3.6$ & $\mathbf{3 1 . 3 \pm 3 . 9 *}$ \\
Sleep problems index & $30.6 \pm 2.7$ & $28.4 \pm 2.5$ & $27.6 \pm 2.8$ \\
\hline
\end{tabular}

Data presented as mean \pm SD. Among subscores within the MOS-SS, only sleep disturbance improved at visit 3 in the patient population. Data with statistical significance are displayed in bold. To maintain brevity, questions not achieving statistical significance (other than the overall sleep problems index) are not presented. *Matched ANOVA: $P<0.05$ between visits 1 and 3

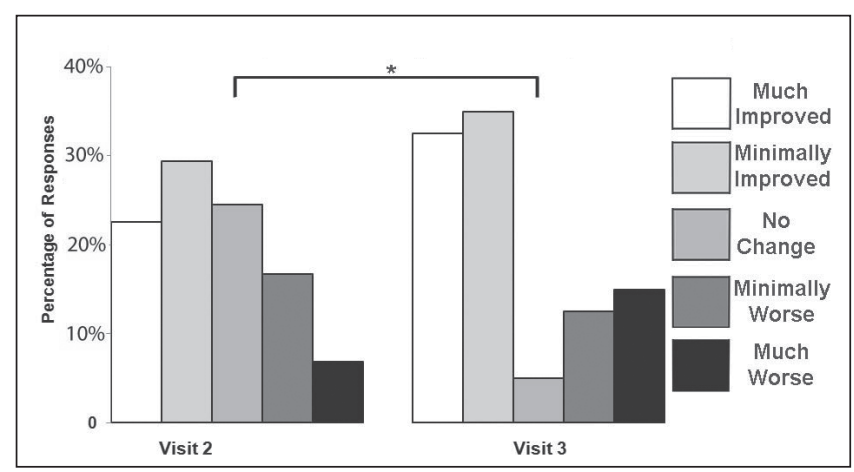

Figure 5) Patient Global Impression of Change score reported by each neuropathic pain patient after follow-up visits. A significant perceived benefit was demonstrated for scores obtained at visit 3 compared with visit 2 (modified ridit [Relative to an Identified Distribution] transformation with the Cochran-Mantel-Haenszel procedure, adjusting for centre in each case: $* P<0.05)$

Multiple disciplines can assist with the numerous goals of the interdisciplinary clinic. Most patients with NeP demonstrate general avoidance of physical activity due to fears of exacerbating their condition or accumulating additional injuries. Kinesiologists are able to conduct functional assessments, provide education and counselling, and help in the construction of a physical activity 


\section{TABLE 6}

Health care resources use (HCRU) scores in patients enrolled in the Neuropathic Pain Clinic (Calgary, Alberta)

\begin{tabular}{lccc}
\hline HCRU criterion & Visit 1 & Visit 2 & Visit 3 \\
\hline Outpatient surgeries or procedures* $^{*}$ & $0.94 \pm 0.19$ & $0.75 \pm 0.28$ & $\mathbf{0 . 5 2} \pm \mathbf{0 . 1 8 ^ { \dagger }}$ \\
Emergency room admissions* $^{\star}$ & $0.87 \pm 0.16$ & $0.64 \pm 0.20$ & $\mathbf{0 . 4 4 \pm 0 . 1 4 ^ { \dagger }}$ \\
Number of other outpatient doctor visits & $3.8 \pm 1.2$ & $2.4 \pm 1 . \mathbf{1}^{\ddagger}$ & $\mathbf{1 . 7 \pm 1 . \mathbf { 1 } ^ { \dagger }}$ \\
\hline
\end{tabular}

Data presented as mean $\pm S D$. Bonferroni corrections were applied for the 15 different questions posed over one calendar year. Data with statistical significance are displayed in bold. To maintain brevity, questions not achieving statistical significance are not presented. ${ }^{*}$ Assessment was over the previous calendar year; ${ }^{\dagger}$ Matched ANOVA: $P<0.0033$ between visits 1 and 3 ; ${ }^{\ddagger}$ Matched ANOVA: $P<0.0033$ between visits 1 and 2

plan. Nursing is instrumental in coordinating care and helping to determine which services are required. In addition, nurses evaluate the painful condition, supervise medication planning, and educate patients regarding pain and other potentially related conditions. Social work input is also important for many patients requiring assistance with insurance coverage, mobility, domestic disputes and coping with their medical conditions. Although our clinic is small, these allied health care professionals are instrumental to the care provided for the patients studied. Other examples of health care providers in multidisciplinary pain clinics include physical therapists, occupational therapists, psychologists, pharmacists and dieticians (15). The skills provided by these health care providers enhance the medical profession's ability to deal with the complexities of chronic pain. In the future, the addition of other medical disciplines, such as psychology and pharmacology, to the NePC may further improve patient management.

It is also known that chronic pain patients who attend multidisciplinary clinics have previously been more likely to fail interventions, demonstrate greater opioid usage and analgesic intake, and a higher prevalence of surgical procedures than patients without pain. Compared with patients with chronic pain attending a multidisciplinary clinic, chronic pain patients who do not attend such a clinic experience greater functional impairment, higher levels of emotional problems, more constant pain, more negative attitudes regarding their future, and have been seen by a greater number of physicians, leading to more HCRU $(20,46,47)$. Patients enrolled in the $\mathrm{NePC}$ were also subject to large numbers of outpatient procedures and physician assessments. Patients with chronic pain require more health care services; in our study, patients with $\mathrm{NeP}$ were no exception. A large amount of the health care provided to chronic pain patients is not for the primary pain condition; rather, it is for other indefinable conditions, the condition leading to the pain itself and mental health problems (48-50). This was also the case in our population, which underwent a large number of procedures and hospital admissions unrelated to pain. As health expenditures increase, direct and indirect medical costs related to forms of chronic pain are noteworthy (51-53) and increasing despite the use of evidence-based guidelines $(54,55)$. Indirectly, chronic pain also influences societal costs related to patients' inability to work (2). When one considers that patients who attend a multidisciplinary pain clinic are nearly twice as likely to return to work (25), the long-term cost savings can be substantial. In our population of $\mathrm{NeP}$ patients, there were significant declines over time in the numbers of outpatient procedures, emergency room visits and assessments by physicians other than at the NePC. This may translate to more controlled HCRU among our population; however, it is unlikely that the needs of $\mathrm{NeP}$ patients will ever be reduced to those of patients without chronic pain. In the future, appropriately controlled studies will be more suited to determine the true impact of interdisciplinary clinics on the health care needs of the population of $\mathrm{NeP}$ patients.

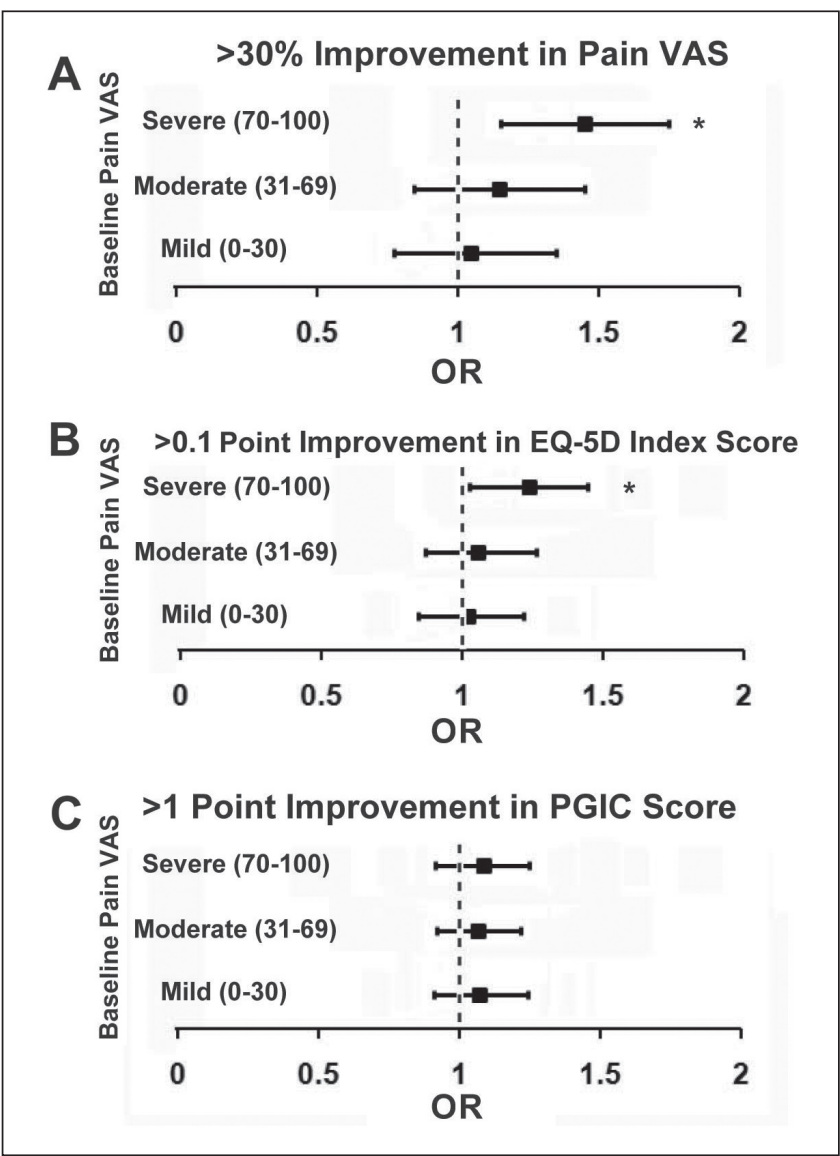

Figure 6) Odds ratios (ORs) are presented as horizontal rectangular bars for patients with a baseline pain severity visual analogue scale (VAS) score that was mild (0 to 30), moderate (31 to 69) or severe (70 to 100). The VAS and European Quality-of-Life Five-Domain (EQ-5D) index scores obtained from visits 1 and 3 at the Neuropathic Pain Clinic (NePC; Calgary, Alberta) were compared. Patient Global Impression of Change (PGIC) scores obtained from visits 2 and 3 at the NePC were also compared. Each OR is presented, along with the $95 \%$ CIs as thin vertical bars stretching right and left of the OR for each category of pain severity. A significant response is present only for the values for which the ORs and 95\% CIs were to the right of the line indicating an OR of 1 (where an OR of 1 equals no discernable effect). A A greater than $30 \%$ improvement of VAS pain severity was selected as a clinically useful indicator of response - only patients with severe pain at baseline had a significant chance of having a greater than 30\% improvement in their VAS pain score. B An increase of greater than 0.1 for the EQ-5D index score was selected as a clinically useful indicator of improvement in quality of life - only patients with severe pain at baseline had a significant chance of improvement of greater than 0.1 in their EQ-5D index score. C An increase of greater than 1 for the PGIC score was selected as a clinically useful indicator of patient satisfaction - pain severity at baseline had no significant impact on an improved PGIC result. $* \chi^{2}(d f=1)$ has a significance of $P<0.05$ for that specific level of pain severity

Comorbidities are prevalent in patients with $\mathrm{NeP}$ - the triad of chronic pain, sleep disturbance and depression/anxiety must be fully considered in the overall management of each patient. These comorbidities negatively impact functionality and quality of life, just as with the pain itself (56). As such, $\mathrm{NeP}$ and its comorbid conditions could represent negatively reinforcing syndromes (57). Depression occurs among patients with chronic pain more so than for other chronic diseases (58), and patients with higher self-rated severities of pain experience a greater degree of anxiety (59). Most chronic pain patients report that sleep difficulties started after initiation 
of chronic pain $(57,59)$, with a positive correlation between pain intensity and degree of sleep disturbance. It is the complexity of comorbidities that contributes to greater HCRU in the NeP population - patients with severe chronic pain make three to four times more visits to physicians and have longer hospital stays than those without chronic pain (60). In our clinic population, between one-third and two-thirds of patients experienced moderate impairment of mood or elevation of anxiety levels. In addition, the sleep problems index scores suggest that similar numbers of patients suffered from concurrent sleep disturbance. Interestingly, enrollment in the NePC led to improvement of anxiety (HADS-A) levels before pain severity was improved. On the surface, one would expect improvements in pain rather than anxiety in an $\mathrm{NeP}$ patient population; however, it is possible that education, reassurance and a complete patient assessment at the $\mathrm{NePC}$ may have relieved some level of anxiety regarding the presenting condition before definite improvements of pain. It is known that anxiety modulates pain threshold, can decrease tolerance to pain (61) and may increase patient self-reported pain ratings (62); therefore, improvement of anxiety first may have led to improvement of pain severity on the third visit to the NePC. Education regarding chronic pain and expectations related to particular conditions also plays a role in patient outcomes. Patients' beliefs pertaining to pain may not be accurate (63), while the attitudes of patients have an impact on clinical status and well-being $(64,65)$.

A major benefit of multidisciplinary clinics such as the NePC is the ability to provide appropriate education that can influence fear-avoidance benefits, possibly reducing costs. We hypothesize that education provided at our clinic contributed to a decline of HCRU over time among $\mathrm{NeP}$ patients who maintained their enrollment at the NePC. Education provided to patients at the NePC not only centred around pain itself, it also explained comorbid psychiatric and sleep disturbances, and the nature of the underlying condition causing the pain. Overall, the decreased HCRU is a positive outcome; however, measures such as HCRU are still subject to recall bias and levels of uncertainty.

There are a number of limitations associated with the present study's results. First, there was no patient group available for comparison that did not access an interdisciplinary clinic. The lack of an appropriate control group makes it difficult to determine whether some of the reported changes are absolutely related to the interventions offered at the NePC. For example, it is possible that the decreased number of outpatient procedures, emergency room admissions and outpatient doctor visits over time may have been related to patients determining futility of these interventions, rather than the impact of the $\mathrm{NePC}$ on their care. Although we chose to analyze timepoints before the clinic visit to permit collection of data before enrollment in the NePC, anticipation of potential results may have impacted the obtained results at times of data collection. We are a small interdisciplinary clinic lacking psychiatrist, psychologist, anesthetist, physical therapist and occupational therapist input pertaining to $\mathrm{NeP}$ patient management, which may have limited the positive results observed. Although all patients were encouraged to use conservative measures to assist with $\mathrm{NeP}$ relief, including aerobic forms of exercise, there was no method to have a control for nonpharmaceutical interventions, or interventions that may have been received at other locations. It was also difficult to control for patients who used additional over-the-counter medications for pain relief without reporting thir use. It is very important to remember that the majority of patients assessed at the NePC had been assessed by a number of other physicians, receiving numerous medications and interventions for a condition that had already been present for years. Patients were already receiving numerous medications on their initial assessment in this real-world study, making it very difficult to compare our results with strictly performed randomized, controlled trials. As a result, the degrees of improvement in scales assessing pain and related comorbidities were small in the present study. Although patient satisfaction may be the distinguishing outcome among treatments with comparable efficacy (66) and provides information regarding treatment effectiveness (67), it is subject to wide distributions of responses, often decreasing the effect size (40). Our data did not show significant changes in a number of categories within the PTSS; however, they did demonstrate changes in the EQ-5D, which is an important quality-of-life measure for cost-effectiveness analyses (68). Finally, patients referred to our tertiary care clinic may not have been representative of the general population of patients with $\mathrm{NeP}-$ it is known that not all chronic pain patients will attend multidisciplinary clinics (69).

\section{CONCLUSION}

Although our data are complicated by the absence of an adequate control group for comparison, we demonstrated the ability of an interdisciplinary clinic specialized in $\mathrm{NeP}$ diagnosis and management to improve patient outcomes with respect to pain, anxiety and quality of life. These measures demonstrated improvement despite the inclusion and carry forward of data related to patients lost to follow-up, and were also associated with a positive self-reported PGIC. Small, but significant, reductions of some measures of HCRU also occurred over time. Beneficial changes were modest in our patient population due to the duration of the condition, previous management being received and potentially ongoing, and due to the complexity of the condition itself. We hypothesize that these multiple and varied improvements are sustainable; however, only studies with longer durations will determine this.

ACKNOWLEDGEMENTS: This study was supported by unrestricted grants through the Department of Clinical Neurosciences, Faculty of Medicine, University of Calgary; Pfizer Canada; and Valeant Canada.

DISCLAIMERS: Dr Toth receives salary support from the Alberta Heritage Foundation for Medical Research, and has provided medical education seminars and advertising boards for Pfizer Canada, Valeant Canada and Boehringer Ingelheim (Canada) Ltd.

\section{APPENDIX}

Conditions present in all 252 enrolled patients with neuropathic pain were tabulated. Rheumatological disease was present (37 patients with osteoarthritis and two patients with rheumatoid arthritis). The mean $( \pm \mathrm{SD})$ creatinine level was $88.5 \pm 23.5 \mu \mathrm{mol} / \mathrm{L}$, with an elevated creatinine level associated with a depressed creatinine clearance found in four patients, all of whom had this condition attributed to diabetic nephropathy. Thyroid disease with replacement therapy was frequently present (41 patients). There were six patients with untreated benign thyroid cysts and four patients with resolved Hashimoto thyroiditis. Anemia was present in 24 patients (12 patients with iron-deficiency anemia, 10 patients with anemia of chronic disease and two patients with hereditary spherocytosis). There were individuals with at least one previous diagnosis of cancer (colon $[n=7]$, prostate $[n=1]$, breast $[n=7]$, vulvar dysplasia $[n=4]$, basal cell carcinoma $[n=3]$ or uterine $[n=3])$. Other conditions present were hypertension $(n=62)$, hyperlipidemia $(n=35)$, migraine $(n=32)$, osteoporosis $(n=18)$, thromboembolism $(n=5)$, nephrolithiasis $(n=4)$, benign prostatic hypertrophy $(n=2)$, coronary artery disease $(n=2)$, Morton's neuroma with resection $(n=2)$ and asthma $(n=2)$. Previously clinically diagnosed psychiatric conditions were diagnosed in 52 patients (major depression [ $n=38]$, anxiety [n=32] and bipolar disorder $[\mathrm{n}=12])$.

Concomitant medications used for conditions other than pain included statins, anticoagulants, angiotensin-converting enzyme inhibitors or angiotensin receptor blockers, beta-blockers, proton pump inhibitors, calcium channel blockers and other miscellaneous drugs. 


\section{REFERENCES}

1. Siddall PJ, Cousins MJ. Persistent pain as a disease entity: Implications for clinical management. Anesth Analg 2004;99:510-20.

2. Henry JL. The need for knowledge translation in chronic pain. Pain Res Manage 2008;13:465-76.

3. Gatchel RJ. A biopsychosocial overview of pretreatment screening of patients with pain. Clin J Pain 2001;17:192-9.

4. Niv D, Devor M. Chronic pain as a disease in its own right. Pain Pract 2004;4:179-81.

5. Moulin DE, Clark AJ, Speechley M, Morley-Forster PK. Chronic pain in Canada - prevalence, treatment, impact and the role of opioid analgesia. Pain Res Manage 2002;7:179-84.

6. International Association for the Study of Pain. <www.iasp-pain. org//AM/Template.cfm?Section=Home $>$ (Accessed on May 4, 2011).

7. Hughes RA. Peripheral neuropathy. BMJ 2002;324:466-9.

8. Backonja MM, Galer BS. Pain assessment and evaluation of patients who have neuropathic pain. Neurol Clin 1998;16:775-90.

9. Gordon A, Choiniere M, Collet JP. The humanistic burden of neuropathic pain in Canada. Journal of Outcomes Research 2006;2006:23-35.

10. Mauskopf J, Austin R, Dix L, Berzon R. The Nottingham Health Profile as a measure of quality of life in zoster patients: Convergent and discriminant validity. Qual Life Res 1994;3:431-5.

11. McDermott AM, Toelle TR, Rowbotham DJ, Schaefer CP, Dukes EM. The burden of neuropathic pain: Results from a cross-sectional survey. Eur J Pain 2006;10:127-35.

12. Meyer-Rosberg K, Kvarnstrom A, Kinnman E, Gordh T, Nordfors LO, Kristofferson A. Peripheral neuropathic pain a multidimensional burden for patients. Eur J Pain 2001;5:379-89.

13. International Association for the Study of Pain. Desirable characteristics for pain treatment facilities - guidelines. $<$ www.halcyon.com/iasp/desirabl.html> (Accessed January 2010).

14. Ospina M, Harstall C. Multidisciplinary Pain Programs for Chronic Pain: Evidence from Systematic Reviews. HTA 30: Series A. Edmonton: Alberta Heritage Foundation for Medical Research, 2003.

15. Peng P, Stinson JN, Choiniere M, et al. Role of health care professionals in multidisciplinary pain treatment facilities in Canada. Pain Res Manage 2008;13:484-8.

16. Rudin NJ. Chronic pain rehabilitation: Principles and practice. WMJ 2001;100:36-43, 66.

17. Texidor MS, Taylor CL. Chronic pain management: The interdisciplinary approach and cost effectiveness. In: Anchor KN, ed. The Handbook of Medical Psychotherapy: Cost Effective Strategies in Mental Health. Lewiston: Hogrefe \& Huber, 1991:89-99.

18. Gardea MA, Gatchel RJ. Interdisciplinary treatment of chronic pain. Curr Rev Pain 2000;4:18-23.

19. Harden RN, Cole PA. New developments in rehabilitation of neuropathic pain syndromes. Neurol Clin 1998;16:937-50.

20. Clark TS. Interdisciplinary treatment for chronic pain: Is it worth the money? Proc (Bayl Univ Med Cent) 2000;13:240-3.

21. Fishbain DA, Lewis J, Cole B, et al. Multidisciplinary pain facility treatment outcome for pain-associated fatigue. Pain Med 2005;6:299-304.

22. Joos B, Uebelhart D, Michel BA, Sprott H. Influence of an outpatient multidisciplinary pain management program on the health-related quality of life and the physical fitness of chronic pain patients. J Negat Results Biomed 2004;3:1.

23. Kitahara M, Kojima KK, Ohmura A. Efficacy of interdisciplinary treatment for chronic nonmalignant pain patients in Japan. Clin J Pain 2006;22:647-55.

24. Robbins J. The evolution of swallowing neuroanatomy and physiology in humans: A practical perspective. Ann Neurol 1999;46:279-80.

25. Flor H, Fydrich T, Turk DC. Efficacy of multidisciplinary pain treatment centers: A meta-analytic review. Pain 1992;49:221-30.

26. Stieg RL. The cost-effectiveness of pain treatment: Who cares? Clin J Pain 1990;6:301-4.

27. Cicala RS, Wright H. Outpatient treatment of patients with chronic pain: An analysis of cost savings. Clin J Pain 1989;5:223-6.

28. Karjalainen K, Malmivaara A, Van Tulder M, et al. Multidisciplinary rehabilitation for fibromyalgia and musculoskeletal pain in working age adults. Cochrane Database Syst Rev 2000;(2):CD001984.
29. Guzman J, Esmail R, Karjalainen K, Malmivaara A, Irvin E, Bombardier C. Multidisciplinary bio-psycho-social rehabilitation for chronic low back pain. Cochrane Database Syst Rev 2002;(1):CD000963.

30. Stones RW, Mountfield J. Interventions for treating chronic pelvic pain in women. Cochrane Database Syst Rev 2000;(4):CD000387.

31. Bouhassira D, Attal N, Alchaar H, et al. Comparison of pain syndromes associated with nervous or somatic lesions and development of a new neuropathic pain diagnostic questionnaire (DN4). Pain 2005;114:29-36.

32. Hadjistavropoulos HD, Clark J. Using outcome evaluations to assess interdisciplinary acute and chronic pain programs. Jt Comm J Qual Improv 2001;27:335-48.

33. Jensen MP, Turner JA, Romano JM, Fisher LD. Comparative reliability and validity of chronic pain intensity measures. Pain 1999;83:157-62.

34. Barkin RL, Lubenow TR, Bruehl S, Husfeldt B, Ivankovich O, Barkin SJ. Management of chronic pain. Part II. Dis Mon 1996;42:457-507.

35. Kind P, Dolan P, Gudex C, Williams A. Variations in population health stuatus: Results from a United Kingdom national questionnaire survey. BMJ 1998;316:736-41.

36. Zelman DC, Gore M, Dukes E, Tai KS, Brandenburg N. Validation of a modified version of the brief pain inventory for painful diabetic peripheral neuropathy. J Pain Symptom Manage 2005;29:401-10.

37. Hays RD, Stewart AL. Sleep measures. In: Stewart AL, ed. Measuring Functioning and Well-Being: The Medical Outcomes Study Approach. Durham: Duke University Press, 1992:235-59.

38. Zigmond AS, Snaith RP. The hospital anxiety and depression scale. Acta Psychiatr Scand 1983;67:361-70.

39. Bouhassira D, Attal N, Fermanian J, et al. Development and validation of the Neuropathic Pain Symptom Inventory. Pain 2004; 108:248-57.

40. Evans CJ, Trudeau E, Mertzanis P, et al. Development and validation of the Pain Treatment Satisfaction Scale (PTSS): A patient satisfaction questionnaire for use in patients with chronic or acute pain. Pain 2004;112:254-66.

41. Hurst $\mathrm{H}$, Bolton J. Assessing the clinical significance of change scores recorded on subjective outcome measures. J Manipulative Physiol Ther 2004;27:26-35.

42. Fordyce WE. Psychological factors in the failed back. Int Disabil Stud 1988;10:29-31.

43. Karjalainen K, Malmivaara A, Van Tulder M, Roine R, Jauhiainen M, Hurri H. Multidisciplinary biopsychosocial rehabilitation for neck and shoulder pain among working age adults. Cochrane Database Syst Rev 2003;(2):CD002194.

44. Harkapaa K, Mellin G, Jarvikoski A, Hurri H. A controlled study on the outcome of inpatient and outpatient treatment of low back pain. Part III. Long-term follow-up of pain, disability, and compliance. Scand J Rehabil Med 1990;22:181-8.

45. Peters J, Large RG, Elkind G. Follow-up results from a randomised controlled trial evaluating in- and outpatient pain management programmes. Pain 1992;50:41-50.

46. Becker N, Bondegaard Thomsen A, Olsen AK, Sjogren P, Bech P, Eriksen J. Pain epidemiology and health related quality of life in chronic non-malignant pain patients referred to a Danish multidisciplinary pain center. Pain 1997;73:393-400.

47. Turk DC, Okifuji A. Efficacy of multidisciplinary pain centres: An antidote to anecdotes. Baillieres Clinical Anaesthesiology 1998;12:103-19.

48. Mantyselka P, Kumpusalo E, Ahonen R, et al. Pain as a reason to visit the doctor: A study in Finnish primary health care. Pain 2001;89:175-80.

49. Engel CC, Von Korff M, Katon WJ. Back pain in primary care: Predictors of high health-care costs. Pain 1996;65:197-204.

50. Luo X, Pietrobon R, Sun SX, Liu GG, Hey L. Estimates and patterns of direct health care expenditures among individuals with back pain in the United States. Spine (Phila Pa 1976) 2004;29:79-86.

51. Barrett AM, Lucero MA, Le T, Robinson RL, Dworkin RH, Chappell AS. Epidemiology, public health burden, and treatment of diabetic peripheral neuropathic pain: A review. Pain Med 2007;8(Suppl 2):S50-62. 
52. Ritzwoller DP, Crounse L, Shetterly S, Rublee D. The association of comorbidities, utilization and costs for patients identified with low back pain. BMC Musculoskelet Disord 2006;7:72.

53. Maniadakis N, Gray A. The economic burden of back pain in the UK. Pain 2000;84:95-103.

54. Asche CV, Kirkness CS, McAdam-Marx C, Fritz JM. The societal costs of low back pain: Data published between 2001 and 2007. J Pain Palliat Care Pharmacother 2007;21:25-33.

55. Martin BI, Turner JA, Mirza SK, Lee MJ, Comstock BA, Deyo RA. Trends in health care expenditures, utilization, and health status among US adults with spine problems, 1997-2006. Spine (Phila Pa 1976) 2009;34:2077-84.

56. Breitbart W, McDonald MV, Rosenfeld B, et al. Pain in ambulatory AIDS patients. I: Pain characteristics and medical correlates. Pain 1996;68:315-21

57. Morin CM, Gibson D, Wade J. Self-reported sleep and mood disturbance in chronic pain patients. Clin J Pain 1998;14:311-4.

58. Banks SM, Kerns RD. Explaining high rates of depression in chronic pain: A diathesis-stress framework. Psychol Bull 1996;119:95-110.

59. Atkinson JH, Ancoli-Israel S, Slater MA, Garfin SR, Gillin JC. Subjective sleep disturbance in chronic back pain. Clin J Pain 1988;4:225-32.

60. Statistics Canada. National Population Health Study - 1994/1995. Ottawa: Statistics Canada, 1995.
61. Kremer E, Atkinson JH, Ignelzi RJ. Measurement of pain: Patient preference does not confound pain measurement. Pain 1981;10:241-8.

62. Cornwall A, Donderi DC. The effect of experimentally induced anxiety on the experience of pressure pain. Pain 1988;35:105-13.

63. Gross DP, Ferrari R, Russell AS, et al. A population-based survey of back pain beliefs in Canada. Spine (Phila Pa 1976) 2006;31:2142-5.

64. Tait RC, Chibnall JT. Attitude profiles and clinical status in patients with chronic pain. Pain 1998;78:49-57.

65. Keeley P, Creed F, Tomenson B, Todd C, Borglin G, Dickens C. Psychosocial predictors of health-related quality of life and health service utilisation in people with chronic low back pain. Pain 2008;135:142-50.

66. Weaver M, Patrick DL, Markson LE, Martin D, Frederic I, Berger M. Issues in the measurement of satisfaction with treatment. Am J Manag Care 1997;3:579-94.

67. Cousins M. Acute and postoperative pain. In: Wall PD, Melzack R, eds. Textbook of Pain. London: Churchill Livingstone, 1994.

68. Weinstein MC, Siegel JE, Gold MR, Kamlet MS, Russell LB. Recommendations of the Panel on Cost-effectiveness in Health and Medicine. JAMA 1996;276:1253-8.

69. TURK D. Interdisciplinary approach to pain management: Philosophy, operations and efficacy. In: Ashburn MA, Rice LJ, eds. The Management of Pain. New York: Churchill Livingstone, 1998:235-48. 


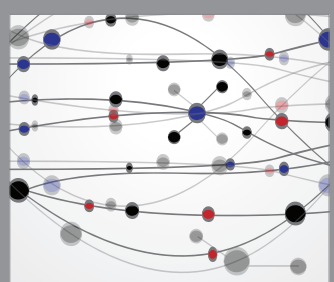

The Scientific World Journal
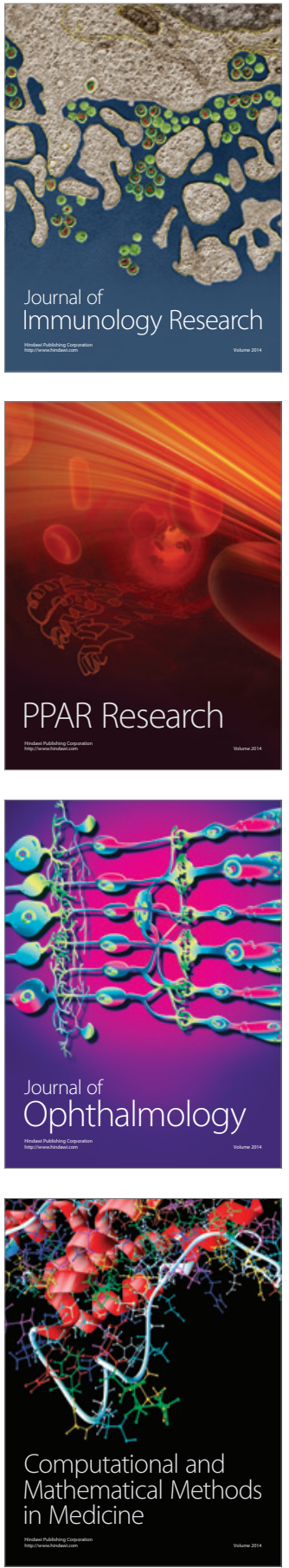

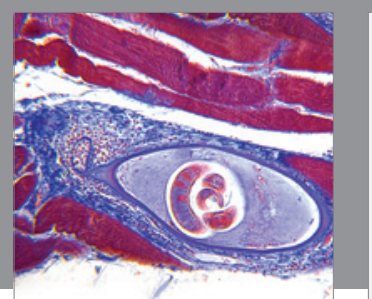

Gastroenterology Research and Practice

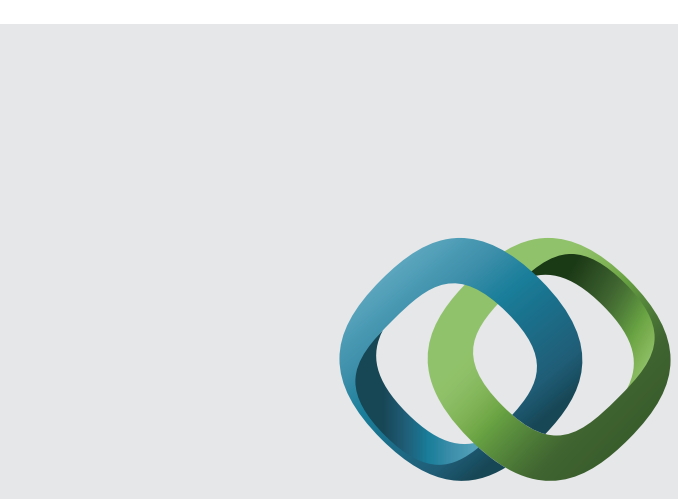

\section{Hindawi}

Submit your manuscripts at

http://www.hindawi.com
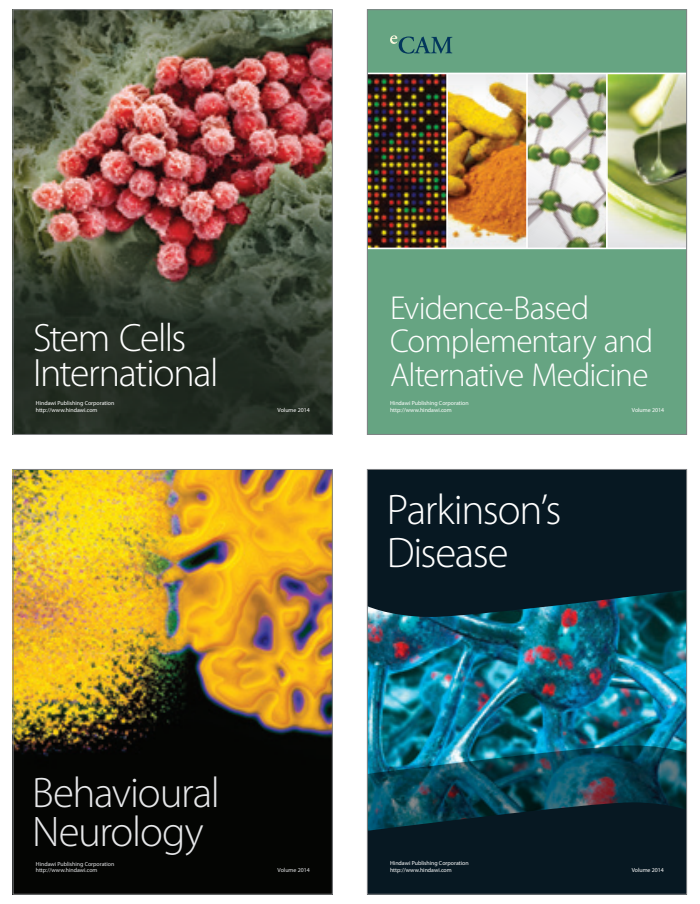
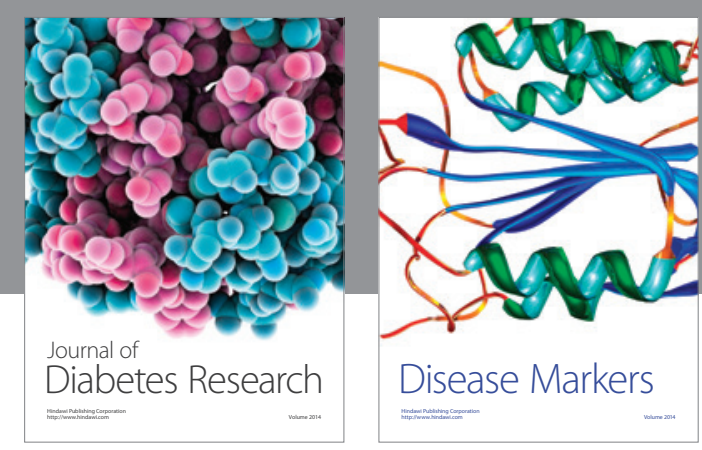

Disease Markers
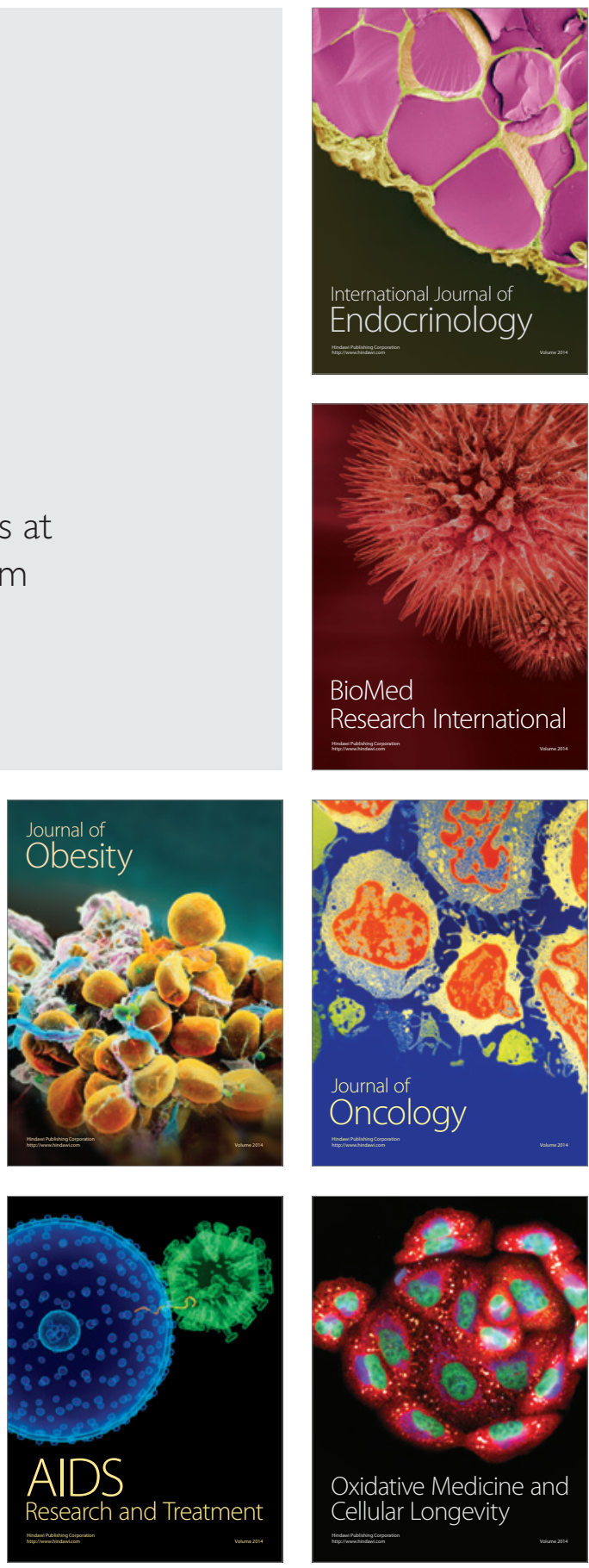